\title{
Preoperative neutrophil-to-lymphocyte ratio is a predictor of survival of epithelial ovarian cancer: a systematic review and meta-analysis of observational studies
}

\author{
Zhuo Yang ${ }^{1}$, Jia-Hui Gu${ }^{1}$, Cui-Shan Guo ${ }^{1}$, Xin-Hui Li ${ }^{1}$ and Wen-Chao Yang ${ }^{1}$ \\ ${ }^{1}$ Department of Obstetrics and Gynecology, Shengjing Hospital of China Medical University, Shenyang, China \\ Correspondence to: Zhuo Yang, email: yangz@sj-hospital.org \\ Keywords: neutrophil, lymphocyte, ovarian cancer, survival, meta-analysis
}

Received: February 10, 2017

Accepted: March 20, 2017

Published: April 03, 2017

Copyright: Yang et al. This is an open-access article distributed under the terms of the Creative Commons Attribution License 3.0 (CC BY

3.0), which permits unrestricted use, distribution, and reproduction in any medium, provided the original author and source are credited.

\section{ABSTRACT}

Inflammation plays an important role in the development and progression of epithelial ovarian cancer (EOC). However, no meta-analysis has comprehensively and quantitatively investigated the prognostic value of the neutrophil-to-lymphocyte ratio (NLR) in EOC patients. Therefore, we performed a meta-analysis to quantify the prognostic impact of this biomarker. We searched the PubMed and Web of Science databases from their inception through December 31, 2016, and examined observational studies evaluating the association of preoperative NLR with progression-free survival (PFS) and overall survival (OS) of EOC patients. A random-effects model was used to summarize hazard ratios (HRs) with $95 \%$ confidence intervals (CIs). Twelve retrospective cohort studies including 3,154 EOC patients were identified. Elevated NLR in EOC patients was associated with worse PFS (summarized HR $=1.80 ; 95 \%$ $C I=1.22-2.65 ; I^{2}=79.1 \%$ ) and OS (summarized HR $=1.72 ; 95 \% \mathrm{CI}=1.18-2.51$; $I^{2}=73.5 \%$ ) compared with low NLR. No evidence of publication bias was detected by funnel plot analysis and formal statistical tests. Although the results were robust in all subgroup analyses, not all results were statistically significant. We determined that adjustments for CA-125 level and performance status might be sources of heterogeneity. These combined results indicate that preoperative NLR is an important predictor of prognosis in EOC patients. Since the high heterogeneity and retrospective study design of included studies, these results require further validation with prospective cohort and trials enrolling larger patient populations and conducting longer follow-up examinations.

\section{INTRODUCTION}

Epithelial ovarian cancer (EOC) is the second-most common gynecological cancer in the world; globally, there were approximately 0.23 million new cases and 0.15 million deaths in 2012 [1]. Primary cytoreductive surgery and platinum-based adjuvant chemotherapy remains the gold standard in treatment for EOC patients [2]. However, the majority of these patients are diagnosed at a later stage, half of the patients experience recurrence within 16 months, and the 5-year overall survival rate is below 50\% [3-6]. The International Federation of Gynecology and Obstetrics (FIGO) established several predictors of survival for EOC patients, including age at diagnosis, stage, histological grade, residual tumor, ascites, performance status (PS), and cancer antigen 125 (CA-125) levels [7, 8]. However, effective biomarkers for individualized prediction of treatment outcomes and prognosis are still urgently required [4].

Inflammation is involved in all stages of cancer formation, including initiation, promotion, development, and progression of EOC [9]. Therefore, systemic inflammatory response (SIR) markers such as hypoalbuminemia, hyperfibrinogenemia, C-reactive protein, absolute white blood cell count, neutrophil-tolymphocyte ratio (NLR), and platelet-to-lymphocyte ratio have been investigated as prognostic factors in cancer patients [10-13]. Among these biomarkers, NLR is a combination of peripheric neutrophils and lymphocytes, which represents the host systemic inflammatory response and the immunity status of the patient [14]. Previous studies hypothesized that increased NLR is associated with some unfavorable clinico-pathological features and 
poor survival of EOC patients [15-17]. However, the relationship between NLR and survival of EOC patients is not consistent in epidemiological studies. Several studies reported that preoperative peripheral blood NLR is an independent predictor of poor prognosis in ovarian cancer [14, 18-24], whereas other studies failed to find any evidence of this association [4, 15-17].

To the best of our knowledge, no systematic review and meta-analysis has investigated the prognostic value of NLR as a predictive biomarker for patients with EOC. The purpose of this study was to summarize the evidence from observational studies for an association of preoperative NLR with progression-free survival (PFS) and overall survival (OS) in EOC patients from observational studies.

\section{RESULTS}

\section{Search results, study characteristics, and quality assessment}

The detailed processes of literature screening, study selection, and study exclusion are summarized in Figure 1. Our initial search retrieved 229 unique reports. After removing duplicates and screening the titles and abstracts, 35 articles were considered as potentially eligible for inclusion, and were subjected to full-text review. After exclusion, 12 observational studies were included in the meta-analysis [4, 14-24].

Table 1 presents the main characteristics of the 12 included studies. These studies were published from 2009 to 2016 , and included a total of 3, 154 ovarian cancer patients with a range of $30-875$ cases in individual studies. These 12 reports were designed as retrospective cohort studies. The majority of the included studies were conducted in Asia $(n=9)[4,14,15,17,19-22,24]$, two were conducted in Europe $[16,18]$, and one was conducted in the United States [23]. Ten studies [4, 14-17, 19-22, 24] treated NLR as a categorical variable, whereas two studies $[18,23]$ treated NLR as a continuous variable. The cut-off values among the 10 studies were defined as follows: 6 studies utilized receiveroperating curve (ROC) [14, 15, 18-20, 22, 24], one study utilized median levels [4] and one study utilized interquartile levels [21], one study utilized the cut-off value defined by a previous study [17], and one study failed to mention this issue [16]. More than half of the included studies adjusted for age at diagnosis/surgery $(n=8)$, FIGO stage $(n=7)$, and CA-125 level $(n=6)$. Fewer studies adjusted for SIR markers $(n=5)$, tumor grade $(n=4)$, and PS $(n=3)$.

The quality assessment characteristics of the included studies are shown in Table 2. The major difference among these included studies was the control for an important factor or an additional factor category; 7 of the included studies were assigned two full scores [4, 14, 16, 18, 21, $23,24]$. The study by Nakamura et al. [20] only reported mortality within 100 days; therefore, this study was not assigned a score when testing for whether the follow-up duration was long enough for outcomes to occur.

\section{Progression-free survival}

Seven retrospective cohort studies including a total of 1,863 patients evaluated the association between NLR

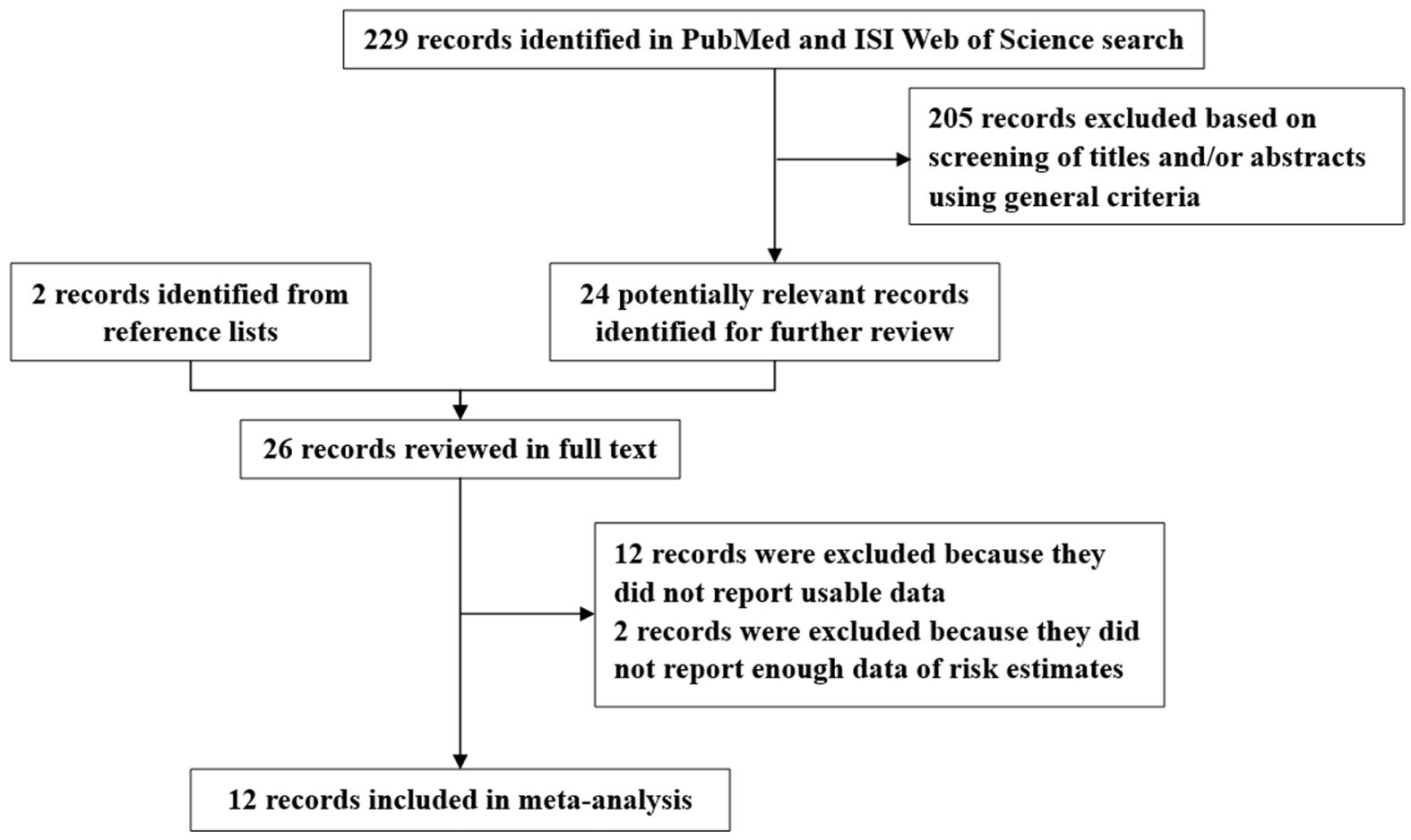

Figure 1: Selection of studies for inclusion in this meta-analysis. 
Table 1: Characteristics of twelve retrospective cohort studies included in the meta-analysis

\begin{tabular}{|c|c|c|c|c|c|c|c|c|c|c|}
\hline \multirow{2}{*}{$\begin{array}{l}\text { First author, [ref], } \\
\text { year, country }\end{array}$} & \multirow{2}{*}{$\begin{array}{l}\text { No. of } \\
\text { cases }\end{array}$} & \multirow{2}{*}{$\begin{array}{c}\text { Exposure } \\
\text { characteristics }\end{array}$} & \multirow{2}{*}{ Outcome } & \multirow{2}{*}{$\begin{array}{c}\text { Hazard ratio } \\
(95 \% \mathrm{CI})\end{array}$} & \multicolumn{6}{|c|}{ Adjustment for potential confounders } \\
\hline & & & & & Age & FIGO & Grade & PS & CA-125 & SIR markers \\
\hline $\begin{array}{c}\text { Badora-Rybicka et al. } \\
\text { [18], 2016, Poland }\end{array}$ & 315 & Continuous & $\begin{array}{l}\text { PFS } \\
\text { OS }\end{array}$ & $\begin{array}{l}1.22(1.08-1.38) \\
1.09(0.98-1.22)\end{array}$ & $\sqrt{ }$ & $\sqrt{ }$ & & $\sqrt{ }$ & $\sqrt{ }$ & \\
\hline $\begin{array}{c}\text { Eo et al. [19], 2016, } \\
\text { Korea }\end{array}$ & 234 & $\begin{array}{c}\text { Category } \\
(\leq 4.28 \text { vs. }>4.28) \\
(\leq 5.03 \text { vs. }>5.03)\end{array}$ & $\begin{array}{l}\text { PFS } \\
\text { OS }\end{array}$ & $\begin{array}{l}2.34(1.45-3.77) \\
2.01(1.18-3.43)\end{array}$ & & & & & & \\
\hline $\begin{array}{c}\text { Feng et al. [4], 2016, } \\
\text { China }\end{array}$ & 875 & $\begin{array}{c}\text { Category } \\
(\leq 3.24 \text { vs. }>3.24)\end{array}$ & $\begin{array}{l}\text { PFS } \\
\text { OS }\end{array}$ & $\begin{array}{l}1.25(1.05-1.48) \\
1.19(0.94-1.50)\end{array}$ & $\sqrt{ }$ & $\sqrt{ }$ & & & & \\
\hline $\begin{array}{l}\text { Nakamura et al. [20], } \\
\text { 2016, Japan }\end{array}$ & 30 & $\begin{array}{c}\text { Category } \\
(\leq 3.91 \text { vs. }>3.91)\end{array}$ & OS & $14.1(1.21-165)$ & $\sqrt{ }$ & & & $\sqrt{ }$ & $\sqrt{ }$ & \\
\hline $\begin{array}{l}\text { Wang et al. [14], } \\
\text { 2016, China }\end{array}$ & 143 & $\begin{array}{c}\text { Category } \\
(\leq 3.43 \text { vs. }>3.43)\end{array}$ & $\begin{array}{l}\text { PFS } \\
\text { OS }\end{array}$ & $\begin{array}{l}3.37(1.39-8.15) \\
2.20(1.03-4.70)\end{array}$ & $\sqrt{ }$ & $\sqrt{ }$ & & & $\sqrt{ }$ & $\sqrt{ }$ \\
\hline $\begin{array}{l}\text { Wang et al. [21], } \\
\text { 2015, China }\end{array}$ & 126 & $\begin{array}{c}\text { Category } \\
(\leq 1.86 \text { vs. }>3.77)\end{array}$ & $\begin{array}{l}\text { PFS } \\
\text { OS }\end{array}$ & $\begin{array}{l}6.87(2.64-17.9) \\
8.57(2.81-26.1)\end{array}$ & $\sqrt{ }$ & $\sqrt{ }$ & $\sqrt{ }$ & $\sqrt{ }$ & $\sqrt{ }$ & $\sqrt{ }$ \\
\hline $\begin{array}{l}\text { Zhang et al. [22], } \\
\text { 2015, China }\end{array}$ & 190 & $\begin{array}{c}\text { Category } \\
(\leq 3.4 \text { vs. }>3.4)\end{array}$ & $\begin{array}{l}\text { PFS } \\
\text { OS }\end{array}$ & $\begin{array}{l}2.01(1.48-2.74) \\
2.17(1.55-3.05)\end{array}$ & & & & & & \\
\hline $\begin{array}{l}\text { Williams et al. [23] } \\
\text { 2014, USA }\end{array}$ & 519 & Continuous & OS & $1.37(1.06-1.76)$ & $\sqrt{ }$ & $\sqrt{ }$ & $\sqrt{ }$ & & $\sqrt{ }$ & \\
\hline $\begin{array}{c}\text { Raungkaewmanee } \\
\text { et al. [15], 2012, } \\
\text { Thailand }\end{array}$ & 166 & $\begin{array}{c}\text { Category } \\
(\leq 2.6 \text { vs. }>2.6)\end{array}$ & $\begin{array}{l}\text { PFS } \\
\text { OS }\end{array}$ & $\begin{array}{l}1.12(0.61-2.07) \\
1.17(0.63-2.19)\end{array}$ & & & & & & \\
\hline $\begin{array}{l}\text { Asher et al. [16], } \\
\text { 2011, United } \\
\text { Kingdom }\end{array}$ & 235 & $\begin{array}{c}\text { Category } \\
(\leq 4 \text { vs. }>4)\end{array}$ & OS & $0.87(0.52-1.44)$ & $\sqrt{ }$ & & $\sqrt{ }$ & & & $\sqrt{ }$ \\
\hline $\begin{array}{l}\text { Thavaramara et al. } \\
\text { [17], 2011, Thailand }\end{array}$ & 129 & $\begin{array}{c}\text { Category } \\
(\leq 2.6 \text { vs. }>2.6)\end{array}$ & $\begin{array}{l}\text { PFS } \\
\text { OS }\end{array}$ & $\begin{array}{l}0.7(0.3-1.4) \\
0.7(0.3-1.6)\end{array}$ & & $\sqrt{ }$ & & & & $\sqrt{ }$ \\
\hline $\begin{array}{c}\text { Cho et al. [24], 2009, } \\
\text { Korea }\end{array}$ & 192 & $\begin{array}{c}\text { Category } \\
(\leq 2.6 \text { vs. }>2.6)\end{array}$ & OS & $8.42(1.09-64.8)$ & $\sqrt{ }$ & $\sqrt{ }$ & $\sqrt{ }$ & & $\sqrt{ }$ & $\sqrt{ }$ \\
\hline
\end{tabular}

Abbreviations: BMI, body mass index; CA-125, carbohydrate antigen-125; CI, confidence interval; FIGO, International Federation of Gynecology and Obstetrics; N/A, not available; PFS, progression-free survival; PS, performance status; OS, overall survival; SIR, systemic inflammatory response.

and PFS of ovarian cancer $[4,14,15,17,19,21,22]$. Compared with the low NLR, elevated NLR indicated worse PFS in ovarian cancer patients (summarized $\mathrm{HR}=1.80 ; 95 \% \mathrm{CI}=1.22-2.65)($ Figure 2$)$, with significant heterogeneity $\left(I^{2}=79.1 \%\right)$ (Supplementary Figures 1 and 2). No evidence of publication bias was indicated by funnel plot analysis (Figure 3 ) and formal statistical tests (Egger test, $P=0.26$; Begg test, $P=$ 0.55 ). The results of subgroup analyses are presented in Table 3. Although the direction of all subgroup analyses consistently indicated that poor PFS was associated with ovarian cancer, not all of them showed statistically significance. Significant results were obtained for differences between adjustments for CA-125 levels in meta-regression analyses. Our sensitivity analysis was performed by excluding one study at a time. The sensitivity analysis showed that the summarized HR for PFS ranged from $1.57\left(95 \% \mathrm{CI}=1.11-2.21 ; I^{2}=3.2 \%\right.$; exclusion of Wang et al. [21]) to $2.03(95 \% \mathrm{CI}=1.36$ $3.03 ; I^{2}=79.9 \%$; exclusion of Thavaramara et al. [17]).

\section{Overall survival}

Eleven retrospective cohort studies including a total of 2, 320 patients evaluated the association of NLR with OS of patients with ovarian cancer $[4,14-17,19-22$, 24]. Compared with low NLR, elevated NLR indicated worse OS in ovarian cancer patients (summarized $\mathrm{HR}=$ $1.72 ; 95 \% \mathrm{CI}=1.18-2.51$ ) (Figure 4), with significant heterogeneity $\left(I^{2}=73.5 \%\right)$ (Supplementary Figure 1). No evidence of publication bias was indicated by visual inspection of a funnel plot analysis (Figure 5) and formal statistical tests (Egger test, $P=0.16$; Begg test, $P=$ $0.15)$. The results of subgroup analyses are presented in Table 3. Although the direction of all subgroup analyses consistently indicated that poor OS was associated with ovarian cancer, not all of them showed statistically significance. Significant results were obtained for differences between adjustments for performance status and CA-125 level in the meta-regression analysis. Our sensitivity analysis was performed by excluding 
Table 2: Methodological quality of twelve retrospective cohort studies included in the metaanalysis

\begin{tabular}{|c|c|c|c|c|c|c|c|c|}
\hline $\begin{array}{l}\text { sFirst author } \\
\text { (reference), year }\end{array}$ & $\begin{array}{c}\text { Representativeness } \\
\text { of the exposed } \\
\text { cohort }\end{array}$ & $\begin{array}{l}\text { Selection } \\
\text { of the } \\
\text { unexposed } \\
\text { cohort }\end{array}$ & $\begin{array}{l}\text { Ascertainment } \\
\text { of exposure }\end{array}$ & $\begin{array}{c}\text { Outcome } \\
\text { of interest } \\
\text { not } \\
\text { present } \\
\text { at start of } \\
\text { study }\end{array}$ & $\begin{array}{l}\text { Control for } \\
\text { important } \\
\text { factor or } \\
\text { additional } \\
\text { factor }^{\dagger}\end{array}$ & $\begin{array}{l}\text { Assessment } \\
\text { of outcome }\end{array}$ & $\begin{array}{l}\text { Follow-up } \\
\text { long enough } \\
\text { for outcomes } \\
\text { to occur }\end{array}$ & $\begin{array}{l}\text { Adequacy } \\
\text { of cohort } \\
\text { follow- } \\
\text { up }\end{array}$ \\
\hline $\begin{array}{l}\text { Badora-Rybicka [18], } \\
2016\end{array}$ & * & * & * & $*$ & $* *$ & $*$ & $*$ & $*$ \\
\hline Eo [19], 2016 & * & $*$ & $*$ & * & - & $*$ & $*$ & $*$ \\
\hline Feng [4], 2016 & * & $*$ & $*$ & * & $* *$ & $*$ & $*$ & $*$ \\
\hline Nakamura [20], 2016 & $*$ & $*$ & $*$ & $*$ & $*$ & $*$ & - & $*$ \\
\hline Wang [14], 2016 & $*$ & $*$ & $*$ & $*$ & $* *$ & $*$ & $*$ & $*$ \\
\hline Wang [21], 2015 & $*$ & $*$ & $*$ & $*$ & $* *$ & $*$ & $*$ & $*$ \\
\hline Zhang [22], 2015 & $*$ & $*$ & $*$ & * & - & $*$ & $*$ & $*$ \\
\hline Williams [23], 2014 & * & * & $*$ & * & $* *$ & $*$ & $*$ & $*$ \\
\hline $\begin{array}{l}\text { Raungkaewmanee } \\
{[15], 2012}\end{array}$ & $*$ & $*$ & $*$ & $*$ & - & $*$ & $*$ & $*$ \\
\hline Asher [16], 2011 & $*$ & $*$ & $*$ & $*$ & $* *$ & $*$ & $*$ & $*$ \\
\hline $\begin{array}{l}\text { Thavaramara [17], } \\
2011\end{array}$ & $*$ & $*$ & $*$ & $*$ & $*$ & $*$ & $*$ & $*$ \\
\hline Cho [24], 2009 & * & - & $*$ & * & $* *$ & $*$ & $*$ & $*$ \\
\hline
\end{tabular}

A study could be awarded a maximum of one star for each item except for the item "Control for important factor or additional factor." The definition/explanation of each column of the Newcastle-Ottawa Scale is available from (http://www. ohri.ca/programs/clinical_epidemiology/oxford.asp).

${ }^{\dagger}$ A maximum of two stars could be awarded for this item. Studies that controlled for age at diagnosis, International Federation of Gynecology and Obstetrics (FIGO) stage received one star, whereas studies that controlled for other important confounders such as residual disease received an additional star.

* A cohort study with a median follow-up time $>24$ months was assigned one star.

$\S$ A cohort study with a follow-up rate $>75 \%$ was assigned one star.

one study at a time, and the results indicated that the summarized HR for OS ranged from 1.50 (95\% $\mathrm{CI}=1.07-2.11 ; I^{2}=66.8 \%$; exclusion of Wang et al. [21]) to $1.91\left(95 \% \mathrm{CI}=1.27-2.86 ; I^{2}=72.8 \%\right.$; exclusion of Asher et al. [16]).

\section{DISCUSSION}

To the best of our knowledge, this is the first systematic review and meta-analysis focusing on the prognostic value of NLR in patients with EOC. The results of this study indicate that, compared with low NLR, elevated NLR was associated with worse PFS and OS in patients with EOC.

The exact mechanisms underlying the association of elevated NLR with the prediction of poor survival in EOC patients have not been determined. Accumulating evidence suggests that inflammation is involved in the initiation, promotion, and progression of cancer [9]. Some studies reported that neutrophils and lymphocytes have prominent roles in inflammatory and immunological responses to tumors [25, 26]; however, they have different functions in the inflammatory response. Neutrophils are the primary source of circulating vascular endothelial growth factor (VEGF), which contributes to tumor-related angiogenesis $[14,27,28]$. Neutrophils also suppress the cytolytic activity of CD8+ T-lymphocyte cells, which effectively delay tumor progression similarly as natural killer cells, and regulate T-cell activation [29, 30]. This creates an immunosuppressive milieu, which is beneficial to tumorigenesis [31, 32]. Conversely, lymphocytes induce cytotoxic cell death and suppress tumor cell proliferation and migration, which are important for defense against cancer proliferation and development [19]. Previous studies have reached a consensus that tumor-infiltrating lymphocytes establish a defense barrier against cancer metastasis [9, 33]. NLR represents a balance between host immunity and tumor angiogenesis, and elevation of NLR would trigger an angiogenic response favorable to tumor cells [14].

Although 10 of the 12 included studies treated NLR as a categorical variable, the cut-off value for NLR varied among these studies due to methodological differences. For example, seven of the included studies $[14,15,18-20$, $22,24]$ optimized NLR cut-off values for outcomes using ROC values ranging from 2.6 to 5.03. By contrast, one study used a median level (3.24) [4] and one study used an 
Table 3: Risk estimates summary of the association of neutrophil-to-lymphocyte ratio with progression-free and overall survival of ovarian cancer patients

\begin{tabular}{|c|c|c|c|c|c|c|c|c|c|c|c|c|}
\hline & \multicolumn{6}{|c|}{ Progression free survival } & \multicolumn{6}{|c|}{ Overall survival } \\
\hline & $\begin{array}{l}\text { No. of } \\
\text { Study }\end{array}$ & HR & $\begin{array}{c}95 \% \\
\text { CI }\end{array}$ & $I^{2}(\%)$ & $\mathbf{P h}^{\dagger}$ & $\mathbf{P h}^{\ddagger}$ & $\begin{array}{l}\text { No. of } \\
\text { Study }\end{array}$ & HR & $\begin{array}{c}95 \% \\
\text { CI }\end{array}$ & $\begin{array}{c}I^{2} \\
(\%)\end{array}$ & $\mathbf{P h}^{\dagger}$ & $\mathbf{P h}^{\ddagger}$ \\
\hline Overall & 7 & 1.80 & $1.22-2.65$ & 79.1 & $<0.01$ & & 10 & 1.72 & $1.18-2.51$ & 73.5 & $<0.01$ & \\
\hline \multicolumn{13}{|l|}{ Subgroup analyses } \\
\hline Number of cases & & & & & & 0.53 & & & & & & 0.41 \\
\hline$\geq 150$ & 4 & 1.61 & $1.14-2.27$ & 74.4 & $<0.01$ & & 6 & 1.48 & $1.04-2.12$ & 70.0 & $<0.01$ & \\
\hline$<150$ & 3 & 2.47 & $0.63-9.672$ & 86.5 & $<0.01$ & & 4 & 2.94 & $0.87-9.96$ & 80.1 & $<0.01$ & \\
\hline $\begin{array}{l}\text { Geographic } \\
\text { location }\end{array}$ & & & & & & N/A & & & & & & 0.35 \\
\hline Asia & 7 & 1.80 & $1.22-2.65$ & 79.1 & $<0.01$ & & 9 & 1.91 & $1.27-2.86$ & 72.8 & $<0.01$ & \\
\hline Europe & 0 & $\mathrm{~N} / \mathrm{A}$ & N/A & N/A & N/A & & 1 & 0.87 & $0.52-1.44$ & $\mathrm{~N} / \mathrm{A}$ & N/A & \\
\hline Cut-off method & & & & & & 0.75 & & & & & & 0.37 \\
\hline ROC & 4 & 1.98 & $1.41-2.78$ & 42.4 & 0.16 & & 6 & 2.03 & $1.44-2.88$ & 32.9 & 0.19 & \\
\hline Non-ROC & 3 & 1.70 & $0.64-4.46$ & 86.0 & $<0.01$ & & 4 & 1.36 & $0.71-2.59$ & 80.0 & $<0.01$ & \\
\hline \multicolumn{13}{|c|}{$\begin{array}{l}\text { Adjustment for potential confounders and risk } \\
\text { factors }\end{array}$} \\
\hline $\begin{array}{l}\text { Age at diagnosis/ } \\
\text { surgery }\end{array}$ & & & & & & 0.31 & & & & & & 0.39 \\
\hline Yes & 3 & 2.85 & $0.95-8.55$ & 87.5 & $<0.01$ & & 6 & 2.28 & $1.17-4.44$ & 77.9 & $<0.01$ & \\
\hline No & 4 & 1.51 & $0.96-2.39$ & 69.0 & 0.02 & & 4 & 1.52 & $0.97-2.39$ & 62.6 & 0.05 & \\
\hline FIGO stage & & & & & & 0.87 & & & & & & 0.73 \\
\hline Yes & 4 & 1.97 & $0.88-4.43$ & 46.4 & 0.16 & & 5 & 2.09 & $0.98-4.48$ & 78.6 & $<0.01$ & \\
\hline No & 3 & 1.84 & $1.29-2.63$ & 84.0 & $<0.01$ & & 5 & 1.60 & $0.99-2.59$ & 69.7 & 0.01 & \\
\hline Tumor grade & & & & & & 0.09 & & & & & & 0.44 \\
\hline Yes & 1 & 6.87 & $2.64-17.91$ & N/A & N/A & & 3 & 3.52 & $0.57-21.94$ & 87.8 & $<0.01$ & \\
\hline No & 6 & 1.57 & $1.11-2.21$ & 73.2 & $<0.01$ & & 7 & 1.57 & $1.10-2.22$ & 65.6 & $<0.01$ & \\
\hline Performance status & & & & & & 0.09 & & & & & & 0.02 \\
\hline Yes & 1 & 6.87 & $2.64-17.91$ & N/A & N/A & & 2 & 9.33 & $3.38-25.77$ & 0 & 0.72 & \\
\hline No & 6 & 1.57 & $1.11-2.21$ & 73.2 & $<0.01$ & & 8 & 1.44 & $1.04-1.99$ & 66.2 & $<0.01$ & \\
\hline CA-125 level & & & & & & 0.04 & & & & & & 0.02 \\
\hline Yes & 2 & 4.70 & $2.34-9.42$ & 12.8 & 0.28 & & 4 & 5.18 & $2.01-13.38$ & 47.3 & 0.13 & \\
\hline No & 4 & 1.45 & $1.03-2.05$ & 73.4 & $<0.01$ & & 6 & 1.32 & $0.94-1.84$ & 69.2 & $<0.01$ & \\
\hline SIR markers & & & & & & 0.53 & & & & & & 0.90 \\
\hline Yes & 3 & 2.47 & $0.63-9.672$ & 86.5 & $<0.01$ & & 5 & 2.05 & $0.83-5.04$ & 80.4 & $<0.01$ & \\
\hline No & 4 & 1.61 & $1.14-2.27$ & 74.4 & $<0.01$ & & 5 & 1.66 & $1.12-2.46$ & 69.9 & 0.01 & \\
\hline
\end{tabular}

Abbreviations: CA-125, carbohydrate antigen-125; CI, confidence interval; FIGO, International Federation of Gynecology and Obstetrics; HR, hazard ratio; N/A, not available; ROC, receiver-operating curve; SIR, systemic inflammatory response. ${ }^{\dagger} P$-value for heterogeneity within each subgroup.

$\$ P$-value for heterogeneity between subgroups with meta-regression analysis.

interquartile level (1.86-3.77, from the lowest to highest category) [21]. We could not distinguish which method was most accurate, and did not find that the cut-off method was a source of heterogeneity in the meta-regression analysis (Table 3). Nevertheless, the heterogeneity between these two groups was obviously different $(42.4 \%$ vs. $86 \% ; 32.9 \%$ vs. 80\%). Future studies are needed to clarify which cut-off method provides the most accurate values for estimating prognostic risk for patients with EOC.

The strengths of our meta-analysis include a large sample size (3154 EOC patients) and no significant evidence of publication bias. All of the included studies 
were published within 8 years (2009 to 2016), and all had performed consistent experimental procedures for measuring NLR. The results of our subgroup and sensitivity analyses were consistent, which suggested that the results were robust. This meta-analysis has several limitations that should be acknowledged. First, the 12 included studies were all designed as retrospective cohort studies, which depended on medical records or documentation and avoided potential

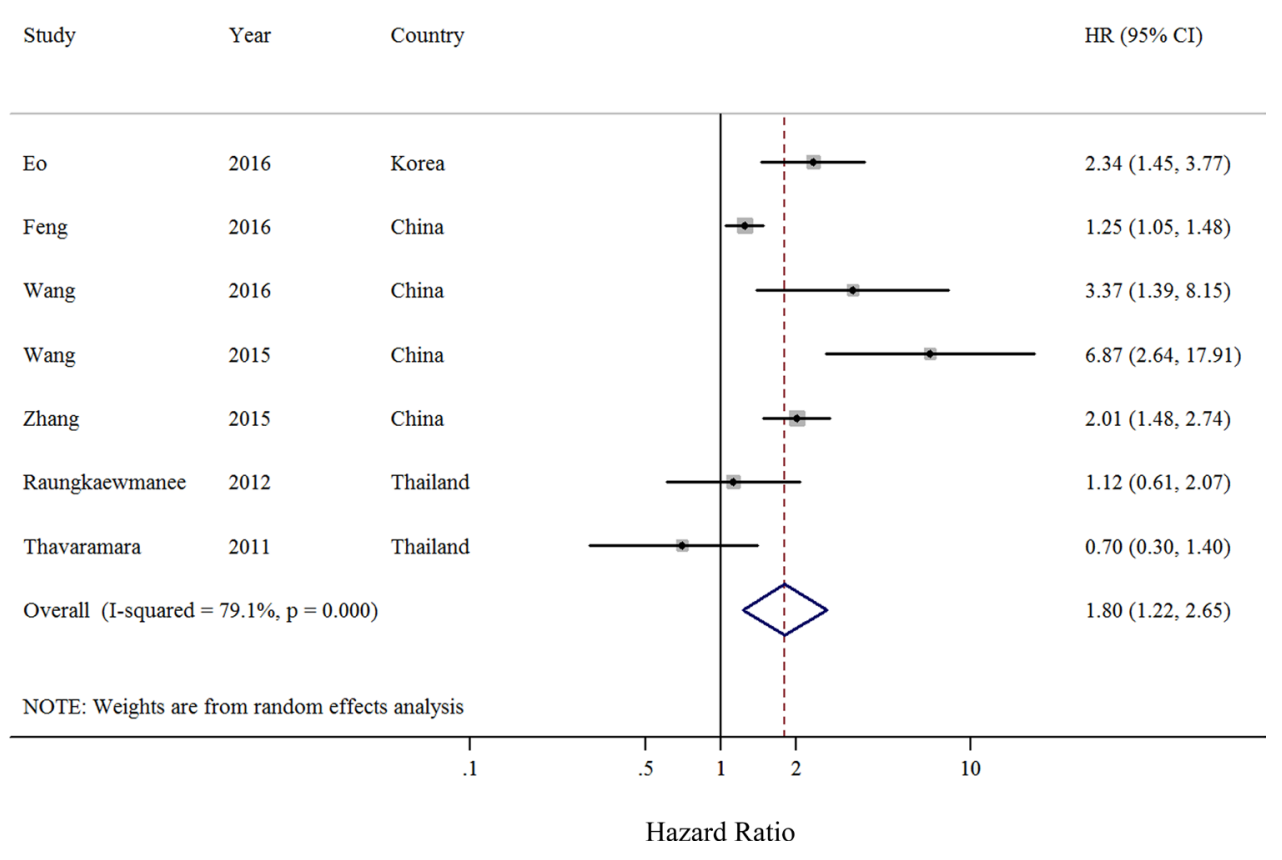

Figure 2: Forest plot (random-effects model) of neutrophil-to-lymphocyte ratio and progression-free survival of patients with ovarian cancer. The squares indicate study-specific hazard ratios (size of the square reflects the study-specific statistical weight); the horizontal lines indicate $95 \% \mathrm{CIs}$; and the diamond indicates the summary hazard ratio estimate with its $95 \% \mathrm{CI}$.

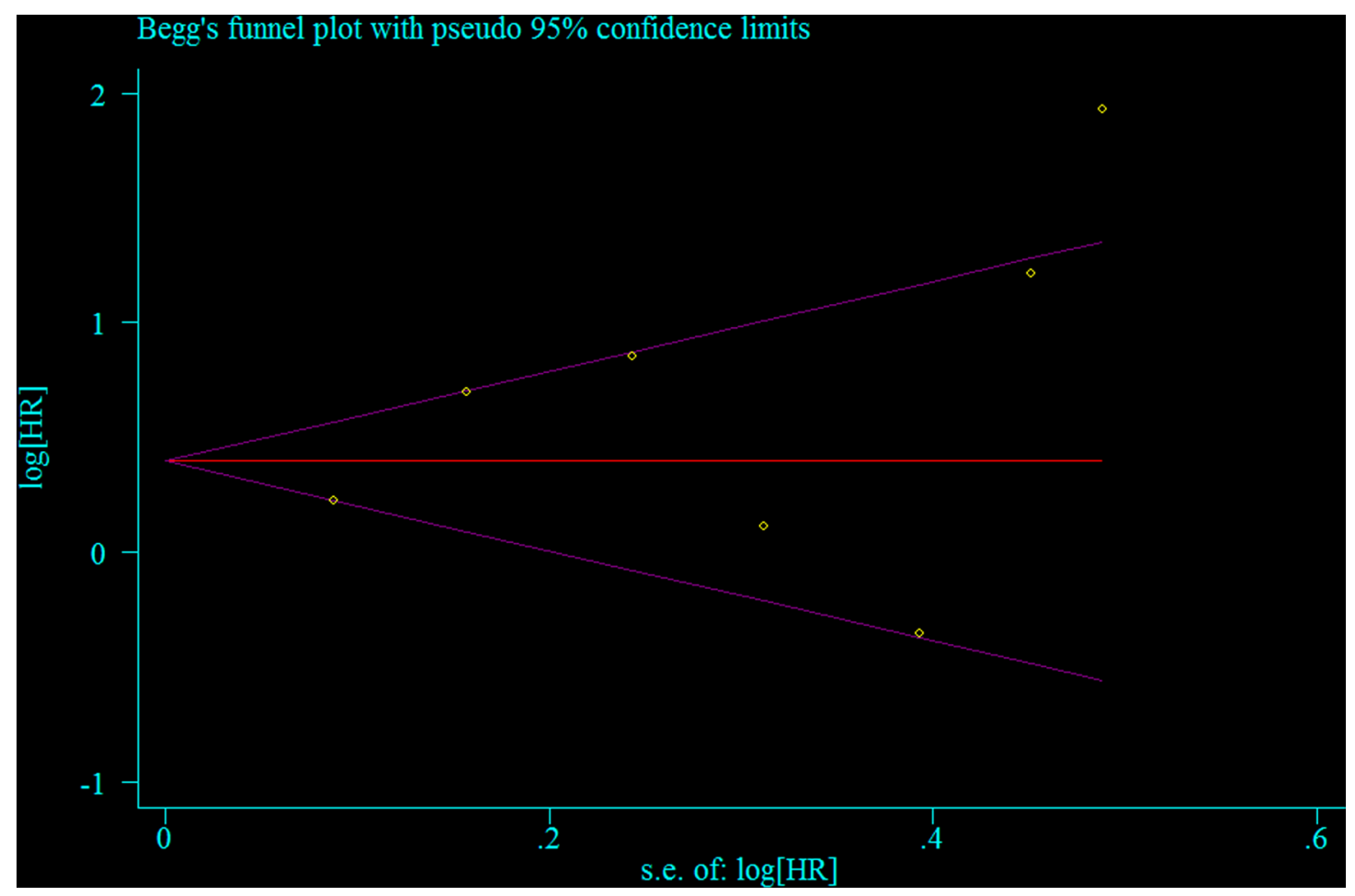

Figure 3: Test for publication bias for progression-free survival through Begg's funnel plot. HR, hazard ratio; SE, standard error. 
recall bias. The results significantly differed according to whether PS and CA-125 levels were adjusted, which suggested that PS and CA-125 levels might be sources of heterogeneity, although we could not rule out the possibility that the limited number of studies for the subgroup analyses might have introduced heterogeneity. Second, 8 meeting abstracts [34-41] failed to provide HR and 95\% CI, or sufficient data to calculate these parameters, and were excluded from the final analysis. Although this limited the sample size of the present meta-analysis, the inclusion of meeting abstracts may lower the meta-analysis quality because they have not undergone rigorous peer review [13]. Third, NLR is associated with many factors such as cigarette smoking, use of non-steroidal anti-inflammatory drugs, chronic infection or inflammatory disease, and PS $[20,23,42,43]$. The retrospective cohort design and the limited number of included studies precluded adjustment for these potential confounders in the primary analyses. Therefore, it is possible that the association between NLR and survival of EOC could result from unmeasured or residual confounding effects due to these factors. Fourth, only two of the included studies $[18,23]$ treated NLR as a continuous variable in the primary multivariate analyses; therefore, we could not evaluate dose-response associations between NLR and survival of EOC patients. Further studies are warranted to obtain sufficient data or conduct doseresponse analyses in the future.

In conclusion, the first systematic review and meta-analysis of observational studies conducted a comprehensive and quantitative investigation into the association between NLR and survival of EOC patients.
We found that increased NLR was significantly associated with worse PFS and OS in patients with EOC, compared with low NLR. Since the high heterogeneity which might limit the interpretation of this finding, this result requires further validation with prospective cohort and trials enrolling larger patient populations and conducting longer follow-up examinations. NLR may serve as a readily available and cost-effective prognostic marker in clinical practice for EOC.

\section{MATERIALS AND METHODS}

\section{Search strategy}

Two independent investigators ( $\mathrm{ZY}$ and $\mathrm{J}-\mathrm{HG}$ ) systematically searched for relevant epidemiological studies published in PubMed (MEDLINE) and Web of Science databases starting from the time of each database's inception to December 31, 2016. The following search keywords and terms were used: (neutrophil-to-lymphocyte OR neutrophil OR lymphocyte OR NLR) AND (ratio) AND (ovary OR ovarian) AND (cancer OR neoplasms OR carcinoma OR tumor). The meta-analysis was planned, conducted, and reported according to the guidelines of the Meta-Analysis of Observational Studies in Epidemiology (MOOSE) group [44].

\section{Study selection and exclusion}

The following inclusion criteria were used: (i) observational study design; (ii) studies evaluated the

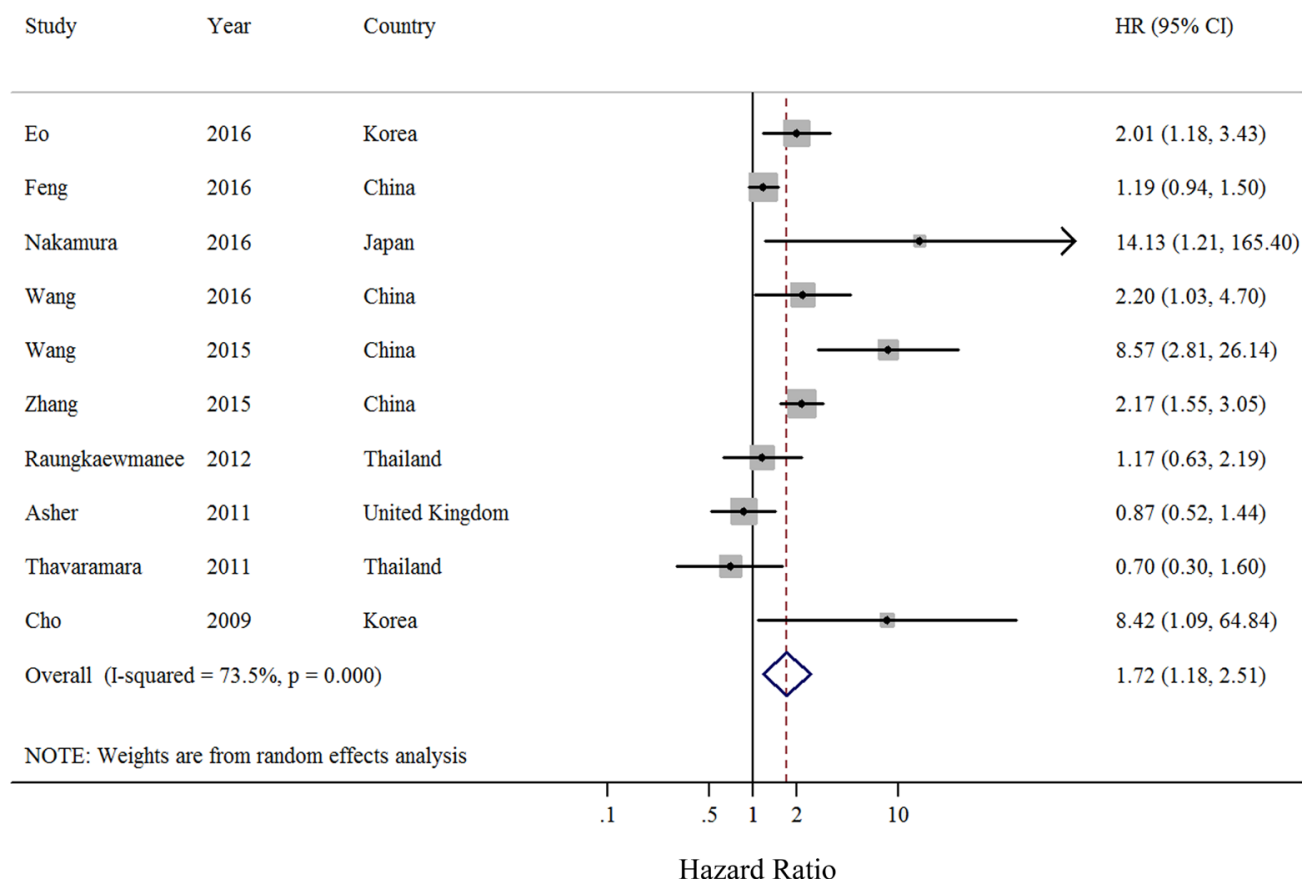

Figure 4: Forest plot (random-effects model) of neutrophil-to-lymphocyte ratio and overall survival of patients with ovarian cancer. The squares indicate study-specific hazard ratio (size of the square reflects the study specific statistical weight); the horizontal lines indicate $95 \%$ CIs; and the diamond indicates the summary hazard ratio estimate with its $95 \%$ CI. 
association of NLR with PFS and OS of ovarian cancer patients; (iii) studies performed hazard ratio (HR) or relative risk (RR) analyses with 95\% confidence intervals (CIs), or reported sufficient data to calculate those risk estimates, and (iv) the NLR was defined as the absolute neutrophil count divided by the absolute lymphocyte count. The following exclusion criteria were used: (i) randomized controlled trials, case-control studies, reviews without original data, ecological studies, editorials, and case reports; (ii) studies that reported risk estimates without $95 \%$ CI (e.g., studies that could not be included in the statistical summary).

We checked titles and abstracts of retrieved articles for relevancy, and then examined the full-text articles. The relevant data were extracted from the complete articles. We also performed manual scans of the bibliographies of the selected articles. The study selection and exclusion procedures were performed by two independent investigators ( $\mathrm{ZY}$ and $\mathrm{J}-\mathrm{HG}$ ).

\section{Data abstraction and quality assessment}

The following information was extracted for each included study by a single investigator (ZY): first author, year of publication, country, number of patients, exposure characteristics, outcomes, and study-specific adjusted risk estimates with 95\% CIs (including adjusted confounder information if applicable). The predefined primary outcome was progression-free survival, and the secondary outcome was overall survival. Extracted data were entered into a standardized Excel (Microsoft) file. Subsequently, an independent investigator ( $\mathrm{J}-\mathrm{HG})$ checked the data, and all differences were resolved by a third investigator (C-SG). Two independent investigators ( $\mathrm{ZY}$ and J-HG) assessed the methodological quality of the included studies according to the Newcastle-Ottawa Scale (NOS) [45-47].

\section{Statistical analysis}

We calculated the summarized HR with $95 \%$ CI by summarizing the risk estimates of each study using a random-effect model to investigate the association of NLR with PFS and OS of patients with ovarian cancer. Only two of the included studies provided sufficient data $[18,23]$; therefore, we were unable to evaluate the dose-response association of NLR with PFS and OS. Heterogeneity across the studies was quantified using the $I^{2}$ statistic, which indicates significant heterogeneity when $I^{2}>50 \%$ [48]. We also conducted post hoc subgroup analyses according to the median number of ovarian cases ( $\geq 150$ vs. $<150)$, country (Asia vs. Europe), cut-off method (ROC vs. non-ROC), and adjustments made for potential confounders (including age at surgery/diagnosis, FIGO stage, tumor grade, PS, CA-125 level, and other systemic inflammatory response markers). Heterogeneity between subgroups was evaluated by meta-regression analysis. Small study biases (e.g., publication bias) were assessed by visually inspecting a funnel plot analysis and by conducting tests according to Begg et al. [49] and Egger et al. [50]. Sensitivity analyses were conducted by removing one study at a time to examine the effect of data from each study on the overall estimate. All statistical analyses were performed using Stata 12.0 (StataCorp LP).

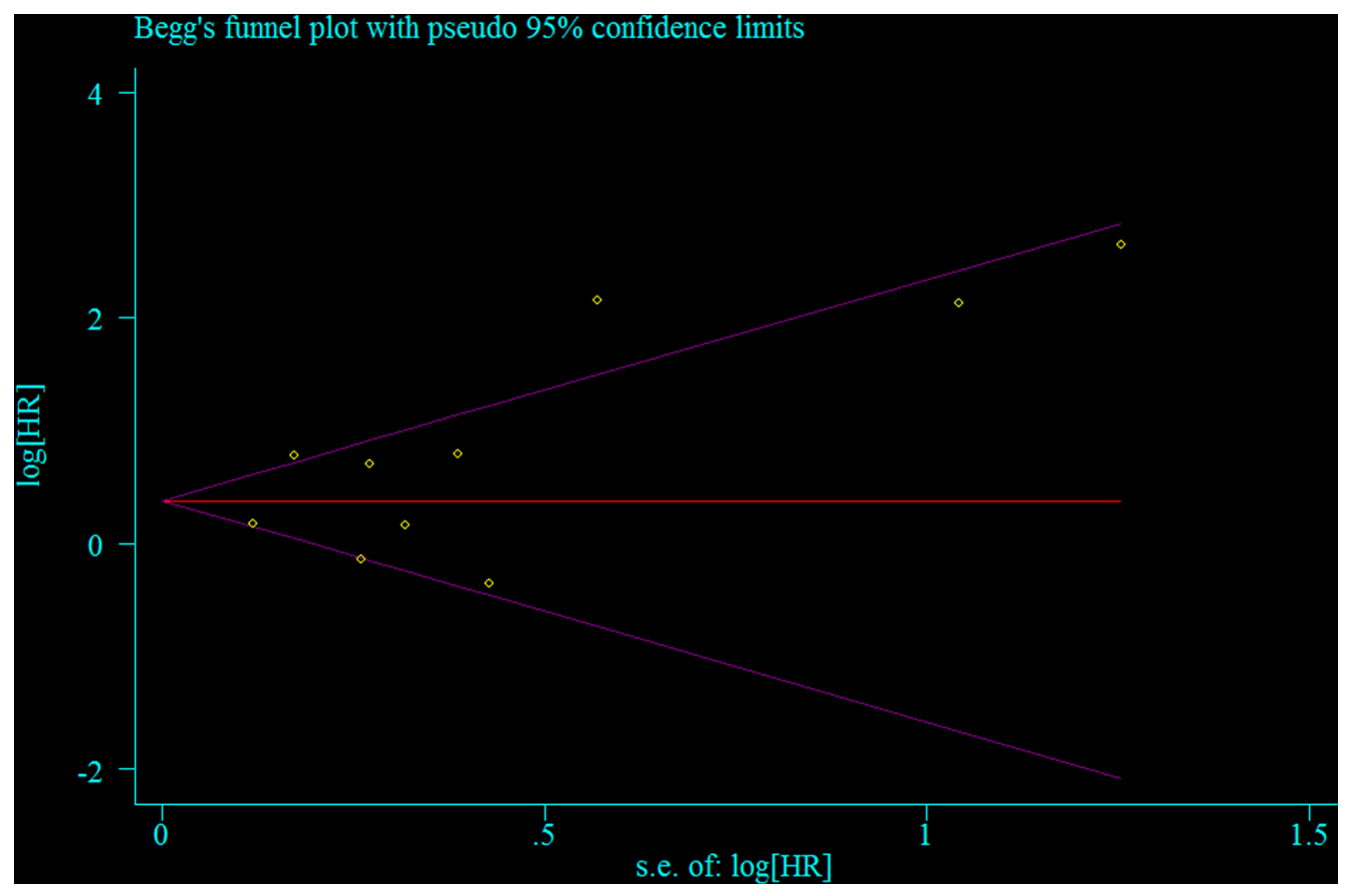

Figure 5: Test for publication bias for overall survival through Begg's funnel plot. Abbreviations: HR, hazard ratio; SE, standard error. 


\section{Authors' contributions}

ZY and J-HG designed the research; ZY, J-HG, $\mathrm{C}-\mathrm{SG}$, and $\mathrm{X}-\mathrm{HL}$ conducted the research; $\mathrm{ZY}$ analyzed data; ZY and J-HG wrote the draft; and all authors read, reviewed, and approved the final manuscript. $Z Y$ had primary responsibility for all final content.

\section{ACKNOWLEDGMENTS}

This work was supported by the Younger Research Fund of Shengjing Hospital (Grant ME66 to ZY).

\section{CONFLICTS OF INTEREST}

None.

\section{FINANCIAL INTEREST}

The authors declare no competing financial interests.

\section{REFERENCES}

1. Torre LA, Bray F, Siegel RL, Ferlay J, Lortet-Tieulent J, Jemal A. Global cancer statistics, 2012. CA Cancer J Clin. 2015; 65:87-108.

2. Fader AN, Rose PG. Role of surgery in ovarian carcinoma. J Clin Oncol. 2007; 25:2873-2883.

3. Markman M, Bundy BN, Alberts DS, Fowler JM, ClarkPearson DL, Carson LF, Wadler S, Sickel J. Phase III trial of standard-dose intravenous cisplatin plus paclitaxel versus moderately high-dose carboplatin followed by intravenous paclitaxel and intraperitoneal cisplatin in small-volume stage III ovarian carcinoma: an intergroup study of the Gynecologic Oncology Group, Southwestern Oncology Group, and Eastern Cooperative Oncology Group. J Clin Oncol. 2001; 19:1001-1007.

4. Feng Z, Wen H, Bi R, Ju X, Chen X, Yang W, Wu X. Preoperative Neutrophil-to-Lymphocyte Ratio as a Predictive and Prognostic Factor for High-Grade Serous Ovarian Cancer. Plos One. 2016; 11:e156101.

5. Berek JS, Crum C, Friedlander M. Cancer of the ovary, fallopian tube, and peritoneum. Int J Gynaecol Obstet. 2015; 131:S111-S122.

6. Ledermann JA, Raja FA, Fotopoulou C, GonzalezMartin A, Colombo N, Sessa C. Newly diagnosed and relapsed epithelial ovarian carcinoma: ESMO Clinical Practice Guidelines for diagnosis, treatment and follow-up. Ann Oncol. 2013; 24:i24-i32.

7. Kodama S, Tanaka K, Tokunaga A, Sudo N, Takahashi T, Matsui K. Multivariate analysis of prognostic factors in patients with ovarian cancer stage I, II. Int J Gynaecol Obstet. 1997; 56:147-153.
8. Vergote IB, Kaern J, Abeler VM, Pettersen EO, De Vos LN, Trope CG. Analysis of prognostic factors in stage I epithelial ovarian carcinoma: importance of degree of differentiation and deoxyribonucleic acid ploidy in predicting relapse. Am J Obstet Gynecol. 1993; 169:40-52.

9. Coussens LM, Werb Z. Inflammation and cancer. Nature. 2002; 420:860-867.

10. Kobayashi T, Teruya M, Kishiki T, Endo D, Takenaka Y, Miki K, Kobayashi K, Morita K. Elevated C-reactive protein and hypoalbuminemia measured before resection of colorectal liver metastases predict postoperative survival. Dig Surg. 2010; 27:285-290.

11. Wu M, Guo J, Guo L, Zuo Q. The C-reactive protein/albumin ratio predicts overall survival of patients with advanced pancreatic cancer. Tumour Biol. 2016; 37:12525-12533.

12. Zhang GM, Zhu Y, Ma XC, Qin XJ, Wan FN, Dai B, Sun LJ, Ye DW. Pretreatment Neutrophil-to-Lymphocyte Ratio: A Predictor of Advanced Prostate Cancer and Biochemical Recurrence in Patients Receiving Radical Prostatectomy. Medicine (Baltimore). 2015; 94: e1473.

13. Templeton AJ, Ace O, McNamara MG, Al-Mubarak M, Vera-Badillo FE, Hermanns T, Seruga B, Ocana A, Tannock IF, Amir E. Prognostic role of platelet to lymphocyte ratio in solid tumors: a systematic review and meta-analysis. Cancer Epidemiol Biomarkers Prev. 2014; 23:1204-1212.

14. Wang YQ, Jin C, Zheng HM, Zhou K, Shi BB, Zhang Q, Zheng FY, Lin F. A novel prognostic inflammation score predicts outcomes in patients with ovarian cancer. Clin Chim Acta. 2016; 456:163-169.

15. Raungkaewmanee S, Tangjitgamol S, Manusirivithaya S, Srijaipracharoen S, Thavaramara T. Platelet to lymphocyte ratio as a prognostic factor for epithelial ovarian cancer. J Gynecol Oncol. 2012; 23:265-273.

16. Asher V, Lee J, Innamaa A, Bali A. Preoperative platelet lymphocyte ratio as an independent prognostic marker in ovarian cancer. Clin Transl Oncol. 2011; 13:499-503.

17. Thavaramara $\mathrm{T}$, Phaloprakarn C, Tangjitgamol S, Manusirivithaya S. Role of neutrophil to lymphocyte ratio as a prognostic indicator for epithelial ovarian cancer. $\mathrm{J}$ Med Assoc Thai. 2011; 94:871-877.

18. Badora-Rybicka A, Nowara E, Starzyczny-Slota D. Neutrophil-to-lymphocyte ratio and platelet-to-lymphocyte ratio before chemotherapy as potential prognostic factors in patients with newly diagnosed epithelial ovarian cancer. ESMO Open. 2016; 1: e39.

19. Eo WK, Chang HJ, Kwon SH, Koh SB, Kim YO, Ji YI, Kim HB, Lee JY, Suh DS, Kim KH, Chang IJ, Kim HY, Chang SC. The Lymphocyte-Monocyte Ratio Predicts Patient Survival and Aggressiveness of Ovarian Cancer. J Cancer. 2016; 7:289-296.

20. Nakamura K, Nagasaka T, Nishida T, Haruma T, Ogawa C, Kusumoto T, Seki N, Hiramatsu Y. Neutrophil to 
lymphocyte ratio in the pre-treatment phase of finalline chemotherapy predicts the outcome of patients with recurrent ovarian cancer. Oncol Lett. 2016; 11:3975-3981.

21. Wang Y, Liu P, Xu Y, Zhang W, Tong L, Guo Z, Ni H. Preoperative neutrophil-to-lymphocyte ratio predicts response to first-line platinum-based chemotherapy and prognosis in serous ovarian cancer. Cancer Chemother Pharmacol. 2015; 75:255-262.

22. Zhang WW, Liu KJ, Hu GL, Liang WJ. Preoperative platelet/ lymphocyte ratio is a superior prognostic factor compared to other systemic inflammatory response markers in ovarian cancer patients. Tumour Biol. 2015; 36:8831-8837.

23. Williams KA, Labidi-Galy SI, Terry KL, Vitonis AF, Welch WR, Goodman A, Cramer DW. Prognostic significance and predictors of the neutrophil-to-lymphocyte ratio in ovarian cancer. Gynecol Oncol. 2014; 132:542-550.

24. Cho H, Hur HW, Kim SW, Kim SH, Kim JH, Kim YT, Lee K. Pre-treatment neutrophil to lymphocyte ratio is elevated in epithelial ovarian cancer and predicts survival after treatment. Cancer Immunol Immunother. 2009; 58:15-23.

25. Lin X, Li W, Lai J, Okazaki M, Sugimoto S, Yamamoto S, Wang X, Gelman AE, Kreisel D, Krupnick AS. Fiveyear update on the mouse model of orthotopic lung transplantation: Scientific uses, tricks of the trade, and tips for success. J Thorac Dis. 2012; 4:247-258.

26. Schreiber RD, Old LJ, Smyth MJ. Cancer immunoediting: integrating immunity's roles in cancer suppression and promotion. Science. 2011; 331:1565-1570.

27. Wang H, Huang X, Zhang J, Shao N, Chen LO, Ma D, Ji C. The expression of VEGF, D114/Notch pathway molecules in ovarian cancer. Clin Chim Acta. 2014; 436:243-248.

28. Xiao WK, Chen D, Li SQ, Fu SJ, Peng BG, Liang LJ. Prognostic significance of neutrophil-lymphocyte ratio in hepatocellular carcinoma: a meta-analysis. BMC Cancer. 2014; 14: 117.

29. Shau HY, Kim A. Suppression of lymphokine-activated killer induction by neutrophils. J Immunol. 1988; 141:4395-4402.

30. Kim R, Emi M, Tanabe K. Cancer immunoediting from immune surveillance to immune escape. Immunology. 2007; 121:1-14.

31. Yamanaka T, Matsumoto $\mathrm{S}$, Teramukai $\mathrm{S}$, Ishiwata $\mathrm{R}$, Nagai Y, Fukushima M. The baseline ratio of neutrophils to lymphocytes is associated with patient prognosis in advanced gastric cancer. Oncology-Basel. 2007; 73:215-220.

32. Azab B, Bhatt VR, Phookan J, Murukutla S, Kohn N, Terjanian T, Widmann WD. Usefulness of the neutrophilto-lymphocyte ratio in predicting short- and long-term mortality in breast cancer patients. Ann Surg Oncol. 2012; 19:217-224

33. Mantovani A, Allavena P, Sica A, Balkwill F. Cancer-related inflammation. Nature. 2008; 454:436-444.
34. Khatib G, Vardar MA, Guzel AB, Kucukgozgulec U, Gumurdulu D, Paydas S. Does Preoperative Neutrophil To Lymphocyte Or Platelet To Lymphocyte Ratios Have A Role In Predicting Borderline Ovarian Tumors? Int J Gynecol Cancer. 2016; 262: 32.

35. Li Z, Hong N, Robertson M, Wang C, Jiang G. Preoperative red cell distribution width and neutrophil-to-lymphocyte ratio predict survival in patients with epithelial ovarian cancer. Int J Gynecol Cancer. 2016; 263: 763.

36. Badora-Rybicka A, Nowara E. Pre-treatment neutrophil to lymphocyte ratio and platelet to lymphocyte ratio as potential prognostic factors in patients with newly diagnosed ovarian cancer. J Clin Oncol. 2015; 33S.

37. Lutrino E, Fontanella C, Andreetta C, Orlando L, Rihawi K, Quaranta A, Bozza C, D’Amico M, Garattini S, Mazzoni E, Merlo V, Chetri M, Ermacora P, et al. Neutrophil-tolymphocyte ratio predicts survival in high-grade ovarian cancer treated with platinum-based chemotherapy. Int J Gynecol Cancer. 2015; 251: 1273.

38. McComiskey M, Iavazzo C, Datta M, Winter-Roach B, Smith M, Slade R, Ryan M. Neutrophil-to-lymphocyte ratio as a predictor of outcome in ovarian cancer patients. Int $\mathrm{J}$ Gynecol Cancer. 2015; 251: 1437.

39. Cetinkaya N, Bas S, Cuylan ZF, Tug M, Meydanli M, Gungor T. The prediction of ovarian carcinoma by preoperative neutrophil to lymphocyte and platelet to lymphocyte ratio in patients with ovarian mass: a preliminary report. Int J Gynecol Cancer. 2014; 244:317-318.

40. Gungor T, Cetinkaya N, Bas S, Ozgu B, Yakut HI. Neutrophil to lymphocyte \& platelet to lymphocyte \& platelet to lymphocyte ratio, platelet volume and platelet distribution width in patients with borderline ovarian tumor (BOTS). Int J Gynecol Cancer. 2014; 244: 150.

41. Jeon YE, Cho H, Kim S, Kim S, Kim J, Kim Y. Diagnostic and prognostic significance of neutrophil/lymphocyte ratio along with CA125 in ovarian cancer. Gynecol Oncol. 2008; 1081: S32-S33.

42. McMillan DC. Systemic inflammation, nutritional status and survival in patients with cancer. Curr Opin Clin Nutr Metab Care. 2009; 12:223-226.

43. Buyukkaya E, Karakas MF, Karakas E, Akcay AB, Tanboga IH, Kurt M, Sen N. Correlation of neutrophil to lymphocyte ratio with the presence and severity of metabolic syndrome. Clin Appl Thromb Hemost. 2014; 20:159-163.

44. Stroup DF, Berlin JA, Morton SC, Olkin I, Williamson GD, Rennie D, Moher D, Becker BJ, Sipe TA, Thacker SB. Meta-analysis of observational studies in epidemiology: a proposal for reporting. Meta-analysis Of Observational Studies in Epidemiology (MOOSE) group. JAMA. 2000; 283:2008-2012.

45. Wells GA, Shea B, O'Connell D, Peterson J, Welch V, Losos M, Tugwell P. The Newcastle-Ottawa Scale (NOS) 
for assessing the quality of nonrandomised studies in metaanalyses. Available from: http:/www.ohri.ca/programs/ clinical_epidemiology (Accessed on 12/March/2017).

46. $\mathrm{Wu} \mathrm{QJ}, \mathrm{Wu} \mathrm{L}$, Zheng LQ, Xu X, Ji C, Gong TT. Consumption of fruit and vegetables reduces risk of pancreatic cancer: evidence from epidemiological studies. Eur J Cancer Prev. 2016; 25:196-205.

47. Gong TT, Li D, Wu QJ, Wang YZ. Cholesterol consumption and risk of endometrial cancer: a systematic review and doseresponse meta-analysis of observational studies. Oncotarget. 2016; 7:16996-17008. doi: 10.18632/oncotarget.7913.
48. Higgins JP, Thompson SG. Quantifying heterogeneity in a meta-analysis. Stat Med. 2002; 21:1539-1558.

49. Begg CB, Mazumdar M. Operating characteristics of a rank correlation test for publication bias. Biometrics. 1994; 50:1088-1101.

50. Egger M, Davey SG, Schneider M, Minder C. Bias in metaanalysis detected by a simple, graphical test. BMJ. 1997; 315:629-634. 